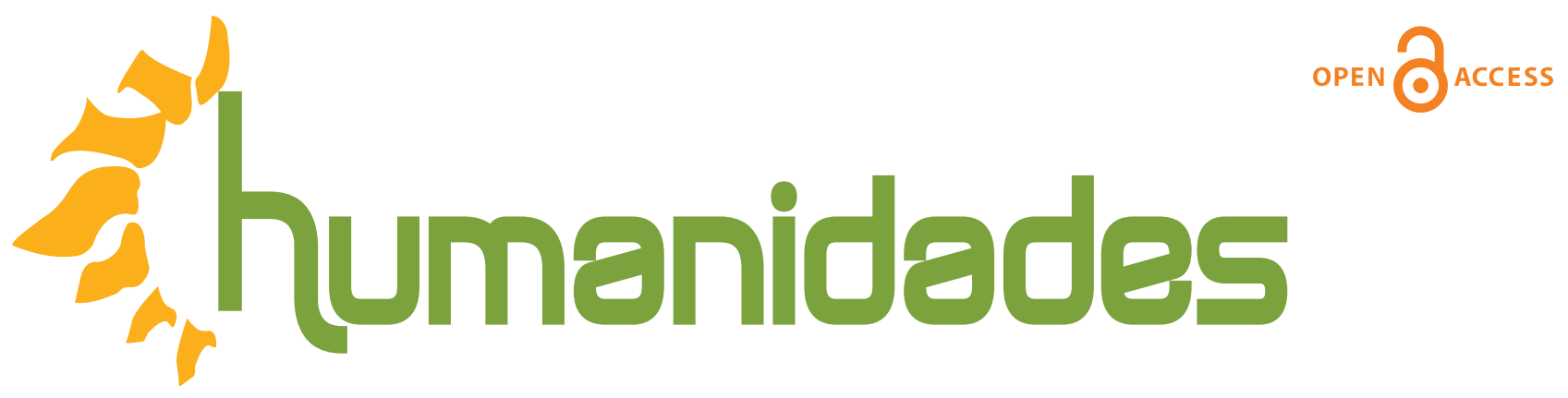

Revista de la Escuela de Estudios Generales, Universidad de Costa Rica

Julio-diciembre, 2019 •Volumen 9, número 2 • EISSN 2215-3934 • pp. 1-21

Recibido: 19-Febrero-2019 Aceptado: 28-Marzo-2019

\title{
Arqueología y curiosidad en el ser humano: la protohistoria de la disciplina científica
}

DOI: https://doi.org/10.15517/h.v9i2.37268

\section{Marta Rojano Simón}

Licenciada en Historia, Máster en Gestión Cultural y Doctoranda en Prehistoria.

Universidad de Córdoba, España

Correo electrónico: 122rosim@uco.es / ymilce@gmail.com

Todos los derechos reservados. Universidad de Costa Rica. Esta revista se encuentra licencida con Creative Commons. Reconocimiento-NoComercial-SinObraDerivada 3.0 Costa Rica. Correo electrónico: humanidades@ucr.ac.cr/ Sitio web: http: //revistas.ucr.ac.cr/index.php/humanidades 


\title{
Arqueología y curiosidad en el ser humano: la protohistoria de la disciplina científica
}

\section{Resumen}

En el presente artículo se pretende esbozar los primeros pasos por los cuales transita la arqueología antes de consolidarse como disciplina científica. Se demostrará que desde las primeras civilizaciones de Oriente Próximo, pasando por ejemplos en las civilizaciones americanas hasta el siglo XIX, la curiosidad del ser humano por conocer sus orígenes a través de las evidencias materiales ha sido una constante. Estos antecedentes remotos constituirán la base sobre la que se configurará la ciencia arqueológica tal y como la conocemos hoy.

\section{Archaeology and the Inquisitiveness on the Human Being: The Scientific Discipline's Protohistory}

\begin{abstract}
The goal of the present paper is to outline the first steps Archaeology took before becoming a scientific discipline. It will be proved that from the first civilizations that populated the Near East area, passing by several examples from the American civilizations till the nineteenth century, human beings have constantly been curious to discover their origins through material evidence. These remote antecedents will constitute the basis upon which the Archaeological science as we know it nowadays will be set.
\end{abstract}

Keywords:

archaeology, prehistory, history, art history

arqueología, prehistoria, historia, historia del arte 


\section{Introducción}

Como se desarrollará a lo largo del artículo, los documentos escritos y restos materiales estudiados por los arqueólogos a partir del siglo XIX nos permiten aseverar que desde las primeras civilizaciones del Próximo Oriente, como Babilonia, Persia o Egipto, el ser humano ha sentido una curiosidad innata por conocer su pasado. Esto le ha llevado a sumergirse en una continua búsqueda de las ideas, los datos y los objetos que caracterizaron la existencia de sus antepasados.

Para lograr estos objetivos, que no son sino los de la Historia, a lo largo del tiempo se han consolidado diversos métodos y técnicas mediante los cuales se recuperan los materiales que permiten al historiador reconstruir el pasado. En el caso específico de los restos materiales, es la arqueología la que desempeña esta función. Así pues, esta ciencia se ha convertido en compañera de viaje del historiador/antropólogo y a lo largo de los diferentes periodos han aparecido numerosas escuelas que se han enfrentado a las problemáticas inherentes a la labor arqueológica de maneras muy diversas. No obstante, a pesar de que nadie dude de su utilidad como instrumento metodológico, o de ciencia aplicada a un período histórico, no existe un consenso internacional sobre el significado preciso del término, ni mucho menos sobre su metodología de trabajo. Como asevera Quirós (2013) "La arqueología está sometida, desde hace algunos años, a profundas tensiones conceptuales, éticas, académicas, profesiones y políticas, como resultado de la crisis y el colapso de una determinada forma de concebir esta disciplina" (p. 13).

Debido al interés del ser humano por explorar su pasado y los objetos que pertenecieron al mismo, la praxis arqueológica antecede al propio desarrollo de la teoría de la disciplina. Este interés se encuentra ligado en su origen a la consideración del ejercicio "arqueológico" como un mero acto relacionado con el comercio, como una actividad impulsada por fines exclusivamente crematísticos o por el interés personal de acumulación y preservación de objetos pertenecientes a culturas anteriores, ya sea como demostración de estatus social o como testigo de un momento histórico que pueda añadir gloria a la estirpe de su poseedor (Renfrew, 1998, p. 20). 
A este respecto encontramos numerosos ejemplos de la recuperación de materiales de civilizaciones antiguas como práctica común de antaño. Como recuerda Vera (2011) "Los primeros documentos donde consta la recuperación y clasificación de restos arqueológicos datan de la época renacentista. Sin embargo, las fuentes insinúan que desde tiempos muchos más remotos ya existía la costumbre de guardar y valorar objetos materiales" (pp. 183-189). A pesar de este interés temprano, no es sino en la primera mitad del siglo XIX cuando la arqueología comienza a tomar cariz científico, a partir de la asimilación de los métodos de otras disciplinas como son la geología o la biología. Aún así, el verdadero interés y auge de la tarea arqueológica se suscita a partir de la Segunda Guerra Mundial.

Siguiendo con lo anterior, desde el comienzo del siglo XIX hasta 1950 la arqueología dispone ya de las características propias de una disciplina científica. A pesar de ello, no existe un debate propiamente dicho en torno a la necesidad de construir un corpus teórico propio. Como hemos expuesto con anterioridad, si bien la arqueología hasta 1950 contaba ya de un rigor científico considerable, es necesario señalar que en cuanto a teoría se refiere y sobre todo a interpretación, los investigadores elaboraban las lecturas de contextos u objetos arqueológicos apoyados en teorías externas, provenientes de otras ciencias, como puede ser la antropología. Esto ocurre en la mayoría de los casos de manera difusa e implícita, debido a la formación primaria de los investigadores de entonces ${ }^{1}$. A partir de 1950 se pone de manifiesto la necesidad de elaborar un corpus teórico independiente e idiosincrático de la arqueología, de modo que comenzaron a configurarse un buen número de tendencias teóricas al amparo de escuelas y paradigmas que han ido transformándose hasta el día de hoy.

\section{La protohistoria de la disciplina científica}

Aunque la arqueología como disciplina científica comienza a partir del siglo XIX consideramos que resulta, de igual modo, interesante remontarnos en nuestro relato a los antecedentes más antiguos de la misma pues son, sin duda, la explicación temprana para comprender por qué disfrutamos hoy de una disciplina con rigor científico. 
En esta sección del artículo expondremos los muy numerosos casos que existen a lo largo de la historia en los que se demuestra que las diferentes civilizaciones de todo el mundo, como son la Babilónica, Azteca, Egipcia, China, Grecia, Roma y Judeocristiana entre otras, tuvieron interés en recuperar artefactos procedentes de su pasado. Ello nos permite trazar una panorámica amplia tanto desde un prisma diacrónico como uno sincrónico.

A pesar de que la historia de la arqueología ha supuesto un fecundo campo de estudio, ampliamente tratado por distintos historiadores a lo largo del tiempo y de que el objeto de estudio no ha sido completamente agotado hasta el día de hoy, nos basaremos en la clasificación de la arqueología llevada a cabo por los doctores Willey y Sabloff (1974). Aunque se publicó hace ya más de cuarenta años, su labor no ha sido superada y, en gran medida, los estudios más recientes no hacen sino partir de los postulados de Willey y Sabloff al estudiar aspectos más geográficamente localizados o especializados desde una perspectiva temática. Estos expertos (que establecen diversas fases de clasificación para la historia de la disciplina) consideran que los antecedentes de esta deben situarse en lo que ellos denominan "etapa especulativa".

Daux en su obra L'etapes de l'archeologie, publicada en Paris en el año 1948, considera que "Antes de llegar a ser ciencia, la arqueología es una actitud" (Alcina, 1989, p. 11). No en vano, ya desde la Edad Antigua se documentan ejemplos incuestionables de la curiosidad del hombre por momentos remotos que venimos explicando. En este sentido, conviene recordar que resulta muy común entre las culturas antiguas de carácter tribal acudir a mitos de creación que se transmiten de generación en generación, a través de relatos orales. Estas narraciones ancestrales desempeñan la función de estatuto mítico para explicar las relaciones sociopolíticas consolidadas en el presente.

En las grandes civilizaciones, los registros escritos nos permiten hablar de una nueva forma de enfocar los orígenes de la civilización y la curiosidad por el pasado desde otra perspectiva. Si bien en este periodo especulativo, la curiosidad por el pasado como explicación de los orígenes del ser humano no está directamente relacionada con la recogida de restos materiales, sí que tenemos documentados casos en los que se da esta suerte de coleccionismo. 
Como ejemplo paradigmático sabemos que algunas tribus del este de Norteamérica recogieron artefactos de una época ignota, que posteriormente fueron encontrados en los yacimientos que excavaron los ingleses durante el siglo XVI (Trigger, 1992, p. 37). De igual modo, el rey Nabónido (último monarca nativo de Babilonia que gobierna entre 555 y 539 a. C) desarrolló un gusto por las antigüedades que lo llevó a intervenir en un templo arcaico y en el almacenamiento de los restos hallados en lo que podríamos llamar el primer museo de la Historia (Renfrew, 1998, p. 20).

En otras culturas se pensaba que los objetos hallados poseían un origen sobrenatural, se les atribuían poderes mágicos y se buscaba su presencia en los rituales religiosos. Aunque escapa del campo de estudio principal de este trabajo, no podemos dejar de señalar la importante labor que llevará a cabo Mircea Eliade al estudiar lo mágico, lo sublime y lo místico a lo largo de las diferentes civilizaciones del pasado. Este es el caso de los rituales aztecas en Teotihuacán, ciudad habitada en el primer milenio. Para sus celebraciones de carácter religioso y mágico los aztecas empleaban artefactos de la cultura olmeca que habían encontrado en este lugar (Morales, 1981, p. 34).

Otra prueba del gusto temprano por las antigüedades lo encontramos en el último periodo del Imperio Egipcio, donde los objetos de los antiguos dirigentes heredaban el valor simbólico de la grandeza nacional. De este modo, pasaban a ser utilizados por los nuevos gobernantes para sustentar su poder e incluso añadían inscripciones con los nombres de sus antepasados en las paredes de las pirámides, templos y monumentos antiguos (Trigger, 1992, p. 40).

En el contexto asiático, el gran historiador chino del siglo II a. C. Sima Qian, visitó y examinó ruinas antiguas y reliquias del pasado para hacer el Shi Ji, la gran compilación de la Historia Antigua de China entre los años 109 y 99 a. C. No obstante, la atención que le dedica a los restos materiales hallados en las ruinas (como pueden ser recipientes de bronce, relieves en jade y obras de arte antiguas) responde más a la curiosidad que al interés científico. Este hecho coincide con la idea que se tenía en Occidente sobre los restos del pasado. Conviene, por otra parte, señalar que esto ocurría especialmente al considerar los objetos muebles, puesto que los monumentos y vestigios inmuebles de civilizaciones pasadas solo tenían una consideración especial para los estudiosos del pasado. 
En la civilización grecorromana la producción escrita de carácter histórico se interesaba sobremanera por el pasado, pero rara vez se sustentaba en el interés por los restos materiales. Sin embargo, tenemos constancia del término "arqueología" haciendo referencia a los hechos del pasado genérico en escritos de eruditos de la Antigüedad como Dionisio de Halicarnaso, Heródoto y Pausanias (Bianchi, 1982, p. 35). Por otra parte, Alcina recoge el gusto de Homero, Plutarco, Vitruvio y Plinio el Viejo por los objetos del pasado, que no dudan en considerarse testigos presenciales de la Historia Antigua (Alcina, 1989, p. 11). Renfrew y Bahn, por su parte, hacen alusión a la obra de Hesíodo Los Trabajos y los Días como evidencia del interés por el pasado histórico, pues en ella se recoge una clasificación del pasado humano en cinco etapas (Renfrew, 1998, p. 20). Interés especial suscita el caso del historiador Tucídides, que realiza una hipótesis deductiva partiendo de los restos materiales hallados en varios enterramientos en la ciudad de Delos. Lleva a cabo una descripción de los objetos encontrados, los identifica como carios y afirma, tras estudiar los hallazgos, que la tribu de los carios pudo habitar la isla en el pasado.

A pesar de que los ejemplos expuestos hasta el momento resultan sin duda ilustrativos, quizá lo más interesante para rastrear los orígenes de la arqueología sea la aparición de la palabra archaeologuia en la introducción a La Historia de la Guerra de Peloponeso. En esta, Tucídides utiliza el término para narrar la reconstrucción del pasado de Grecia hasta el momento de la guerra del Peloponeso; lo que le ocupa 18 capítulos (2-19) y que introduce de la siguiente manera:

\footnotetext{
Pues los sucesos anteriores a estos y los aún más antiguos resultaban imposibles de conocer con detalle a causa del mucho tiempo transcurrido y, a juzgar por los indicios en que me es dado creer cuando miro lo más atrás posible, estimo que no fueron de gran importancia, ni en cuanto a las guerras ni por lo demás (Historia de la Guerra del Peloponeso, Libro I, Cap.45)
}

De igual manera, en la civilización grecolatina encontramos numerosos indicios del interés por las reliquias y los objetos antiguos, que a menudo se plasman en las obras de los grandes eruditos ${ }^{2}$. Resulta importante mencionar que este interés creciente por las antigüedades respondía más a connotaciones económicas y de ostentación social que al desinteresado interés histórico por las culturas a las que pertenecieron dichos objetos. 
Esto se debe a la constancia que tenemos de que las reliquias que se hallaban fortuitamente se vendían a ricos coleccionistas por un precio muy alto y estos las almacenaban como muestra del prestigioso pasado al que pertenecían. Los historiadores, por su parte mencionaban las reliquias como simples curiosidades pues aun no se entendía con claridad la vinculación que los restos materiales mantenían con la historia. Por lo tanto, no se comprendía aún que el hallazgo de antigüedades pudiera ayudar a esclarecer las especulaciones sobre el origen del ser humano, así como las hipótesis que se barajaban acerca de la historia.

Ahora bien, al adentrarnos en la Edad Media, el escaso interés que se había mostrado hasta ese momento por los objetos de arte mueble desaparece casi por completo. Durante este período tan solo interesaban los túmulos, los monumentos megalíticos y las edificaciones antiguas, que eran saqueadas en busca de tesoros, material de construcción y reliquias de carácter religioso. El interés cultural que tenían estos restos antiguos se suscribía al clero, el cual recopilaba cuentos populares referentes a ellos. En este momento las fuentes para el conocimiento del pasado eran exclusivamente la Biblia, los libros de la antigüedad grecorromana y los registros históricos en los que aparecían testimonios de épocas arcaicas. Cabe esperar pues, que en esta época se vinculara el pasado con las fuentes sagradas, que emplazan el origen del hombre de acuerdo con lo que se narra en el primero de los dos relatos contenidos en el Libro del Génesis recogido en la Biblia; que explica el origen del mundo. Comienza así el enfoque creacionista de la historia de la humanidad, que puede ser resumido en seis puntos principales:

- El mundo tenía un origen sobrenatural que no se alejaba más allá de unos pocos miles de años. Las fechas oscilaban entre los 3000 y los 5000 años, hasta que en el siglo XVII el arzobispo James Ussher en su obra Annalium pars Posterior (1654), situó el hito de la creación en el 4004 a. C. A lo largo del siglo XVIII, el marco temporal se amplió progresivamente, hasta situar la creación hacia los 6000 años. Estas aproximaciones fueron realizadas a partir de las genealogías bíblicas. Acogiéndose de nuevo en las fuentes sagradas; se pensaba que el mundo acabaría con el retorno de Jesucristo a la Tierra, tal y como predecía el Libro del Apocalipsis. 
- La Tierra, concedida por Dios, se encontraba en un estado de degeneración progresiva muy cercana a la desaparición. La Biblia atestiguaba que el hombre había estado en el mundo desde su creación y esto garantizaba que tanto el hombre como su entorno se habían degenerado desde el principio. Este tipo de interpretaciones contribuían, sin duda, al soporte de la noción de la transitoriedad de las cosas materiales y de los dogmas sobre los que se sostenía el cristianismo.

- La humanidad fue creada por Dios y expulsada del Edén. Más tarde, Dios castigó al hombre por su degeneración moral con el Diluvio Universal y por su atrevimiento al construir la Torre de Babel con su destrucción y el surgimiento de múltiples lenguajes. El centro de la Historia se encontraba en Próximo Oriente, donde se da origen al judaísmo y desde donde se difunde el cristianismo por Europa. De esta manera, los investigadores de las distintas regiones europeas tratan de vincular su origen con la Historia, construyendo, de este modo, toda una suerte de genealogías que enlazaban a los fundadores de los pueblos y las dinastías reales con personajes de la Historia Sagrada.

- El creacionismo consideraba natural la degeneración de la conducta humana puesto que en el Libro Sagrado se encontraban documentados los cambios, tanto físicos como morales, que le suceden a la humanidad desde el principio mismo, cuando Adán y Eva deben abandonar el Edén como castigo por el incumplimiento de las normas divinas. Esta teoría de la degeneración se utiliza también para explicar el cambio de las tecnologías primitivas (cazadores, recolectores a agricultores y ganaderos) y enlaza con la visión alternativa de historiadores romanos, como Cornelio Tácito, que vinculan la prosperidad material con la depravación moral.

- La Historia se interpretaba como una mera sucesión de acontecimientos que estaban predeterminados por la intervención divina. Así pues, no cabía pensar que el progreso estuviera relacionado con la historia humana, sino que esta transcurría gracias a los designios divinos y se encontraba en constante espera de estos.

- Como se ha manifestado con anterioridad, en la Edad Media la atención hacia los restos materiales resultaba aún menor de la que se prestaba en la Edad Antigua y solo algunos grandes personajes, por lo general vinculados a las coronas reales o divinas, coleccionaban gemas o monedas, reutilizaban obras arquitectónicas previas e imitaban la escultura de la cultura grecolatina.

Siguiendo el esquema cronológico que propone Bruce Trigger (no superado ni puesto en duda hasta la fecha por ningún estudio posterior), a partir del siglo XVI comienzan a desarrollarse los primeros trabajos arqueológicos con dos variables, en función de las fuentes sobre las que se sustente la búsqueda de restos materiales. 
En primer lugar, podemos hablar de la arqueología clásica, asistida por textos escritos que abarcan las civilizaciones contenidas en la Biblia (Mesopotamia, Egipto, Grecia y Roma). Por otra parte, se encuentra el anticuarismo, que se basa en el hallazgo y colección de obras de arte provenientes de las grandes civilizaciones. Una vez más, el interés de los anticuarios por los restos del pasado estaba directamente relacionado con su valor comercial y por el prestigio social que otorgaba su posesión. Por lo tanto, no sentían necesidad alguna de contrastar las piezas con las fuentes escritas.

Existe consenso entre los investigadores para situar el origen de la "arqueología", en particular de su vertiente clásica, en el siglo XVI, momento en el que confluyen el comienzo de la Edad Moderna, el renacimiento de las artes y una mirada hacia la cultura clásica. La revisión de los hechos acontecidos en la civilización grecolatina que se produce en este momento concreto estaba directamente relacionada con la constatación por parte de los investigadores (que llevaban a cabo sus tareas gracias al mecenazgo de la nueva nobleza y burguesía de los Estados que emergen en toda Europa) del retroceso cultural que había supuesto la Edad Media. En consecuencia, este descubrimiento los lleva a buscar con ahínco precedentes en fuentes escritas y materiales que permitieran recuperar los grandes logros de la Antigüedad Clásica mediante la reproducción mimética de los mismos. El aprecio por la antigüedad que se evidencia en los Estados Modernos se centra fundamentalmente en las obras literarias y en los monumentos de valor artístico. De este modo, el término arqueología se enriquece con la concepción artística, además de la vinculación total a la Edad Antigua.

Los grandes mecenas europeos del momento desarrollan un creciente interés por los objetos y edificaciones que hubieron sobrevivido, hasta el punto de organizar expediciones en busca de piezas de valor comercial y estético de los que pudieran hacer ostentación en sus suntuarias colecciones privadas.

La arqueología clásica, heredera directa del interés que nace con el humanismo por conocer los máximos datos y detalles posibles sobre el ser humano desde que este habita la Tierra, se define a la perfección en la siguiente cita de Alcina (1989): 
De todo ello se desprende que la Arqueología en su más primitiva forma, es una arqueología esteticista, clásica y particularista: que se interesa fundamentalmente por la búsqueda de la belleza o de las obras bellas, dentro de los cánones estrictamente clásicos y para los que se dispone de datos tan precisos que permiten la identificación de las obras de autores y talleres concretos, como los de Mirón o Praxíteles. (p. 11)

Como parte de la pulsión que sentían los humanistas por estudiar los restos materiales para obtener mas información del pasado del hombre, debemos hacer referencia al gran humanista Leonardo Da Vinci que, como hiciera en tantos otros campos, se adelanta a su tiempo y arroja algo de luz en lo que al tema que nos ocupa se refiere. Da Vinci procedió a la observación y clasificación de restos fósiles y aventuró la posibilidad de que pudieran provenir de seres vivos muy antiguos que podían servir para atestiguar la antigüedad de la Tierra. De igual modo, se dedicó a observar los sedimentos y sentó las bases de la estratigrafía en el Códice Leicester (Laming-Emperaire, 1984, p. 46).

En el siglo XVIII la Historia del Arte, la arqueología y los textos clásicos se vinculan de manera definitiva en lo que vino en llamarse La Escuela de Arqueología Clásica, gracias a Johann Winckelmann. A partir de incursiones arqueológicas, realizadas en diversos asentamientos grecolatinos, y apoyándose en todo momento en las fuentes escritas, este investigador lleva a cabo una periodización de los estilos escultóricos de Grecia y Roma, con la intención de realizar una clasificación de los modelos universales, de acuerdo con la belleza estética (Alcina, 1989, p. 11). Eric. H. Cline (2018), por su parte, habla de importantes descubrimientos arqueológicos en el siglo XVIII como el hallazgo de trescientos rollos de pergamino antiguo en 1752 por un grupo de arqueólogos italianos (p. 68).

A partir de Winckelmann la escuela clásica continuó su camino hasta mediados del siglo XX. El interés por descubrir los vestigios que citaban las grandes obras clásicas cautivó a numerosos investigadores como es el caso del célebre Heinrich Schliemann (1822-1890), que dedicó su vida y fortuna a encontrar y sacar a la luz las ruinas de la mítica ciudad de Troya (basándose en los indicios contenidos en la Ilíada de Homero) y a reconstruir la ciudad de Micenas, siguiendo la locación que dio Pausanias en el siglo II d. C. 
Por su parte, el arqueólogo inglés Sir Arthur Evans (1851-1941) llevó a cabo una serie de expediciones en Finlandia y los Balcanes; pero donde dieron sus mayores resultados las actividades arqueológicas fue en la ciudad de Cnosos, situada en la isla de Creta, donde en 1900 halló los restos de un gran palacio que identificó con el Palacio de Minos $^{3}$. Así pues, la aportación más significativa al conocimiento de la cultura minoica de Sir Evans consistió en la clasificación cronológica de la civilización cretense, llevada a cabo a partir de los fragmentos de cerámica hallados en el palacio.

La arqueología clásica, muy bien estudiada por Stephen L. Dyson en su seminal obra En busca del pasado clásico: una historia de la arqueología del mundo clásico en los siglos $X I X$ y XX, también fue el modelo de acción para el desarrollo de la egiptología y la asiriología que, a finales del siglo XVIII y durante gran parte del siglo XIX, comienzan a interesarse por desentrañar el halo de misterio que envuelve las civilizaciones de las que solo se tenía constancia de su esplendor en los textos bíblicos.

Las primeras acciones arqueológicas sobre Egipto corrieron a cargo de los investigadores franceses que acompañaban a Napoleón Bonaparte en la invasión de este territorio, entre 1798 y 1799. El hallazgo más importante de estas incursiones fueron las grandes Pirámides y la Piedra Rosetta que, con una inscripción en tres lenguas (jeroglífica, egipcio demótico y griego antiguo) permitió descifrar la escritura jeroglífica. A través de la lectura de la Piedra (descifrada por JeanFrançois Champollion entre 1822 y 1832) y las frecuentes visitas a templos $\mathrm{y}$ monumentos funerarios en busca de fuentes escritas sobre piedra fue posible esbozar una cronología y una evolución histórica del Antiguo Egipto.

Por otra parte, los intentos por traducir la escritura cuneiforme se inician a principios del siglo XIX, aunque no fue hasta 1849 cuando el investigador Harry Rawlison publicó la traducción del texto trilingüe (persa antiguo, babilónico y elamita) que el rey aqueménida Darío I (522-486 a. C) mandó grabar en la roca Behistún para dejar testimonio de las batallas acontecidas durante su reinado. Este avance en el conocimiento de la cultura asiria y babilónica permitió construir una cronología, combinando los hallazgos materiales (templos y palacios con multitud de vestigios materiales) con las fuentes escritas (procedentes en su mayoría de los libros sagrados). 
En los países que conformaban la Europa septentrional y central, el interés por los vestigios del pasado tomó pronto otros derroteros pues los documentos escritos más antiguos eran, con mucha frecuencia, tan solo de época romana. Por lo tanto, cuando en el siglo XVI la arqueología clásica se encuentra en pleno auge en el ámbito mediterráneo, en la Europa Noroccidental se seguía dando credibilidad a la tradición cristiana de época medieval que situaba la creación del hombre hacía unos 6000 años.

Así pues, no resulta extraño que grandes personalidades de todas las ramas de la cultura en estos países aludieran a la cronología tradicional. Como ejemplo paradigmático podemos citar el siguiente pasaje de la obra de William Shakespeare As you like it: "No, faith, die by attorney. The poor world is almost six thousand years old, and in all this time there was not any man died in his own person, videlicet, in a love-cause" (IV. I. 84-128).

A partir del siglo XVI surgen en Inglaterra crónicas de cariz nacionalista en las que se hace referencia a un pasado mítico (en el que destaca de manera prominente la figura del Rey Arturo y la ingente cantidad de relatos vinculados al mismo que componen los diferentes ciclos artúricos) reconstruido a través de objetos materiales. No resulta, por lo tanto, sorprendente que se asocien estos relatos legendarios con monumentos mucho más antiguos que poco tenían que ver con el mítico monarca, como es el caso de Stonehenge ${ }^{4}$.

El descubrimiento de América propició la aparición de las primeras colecciones de antigüedades en las Cortes Europeas que se extendieron a lo largo del siglo XVII. Estas colecciones eran a menudo fruto de cortesías y regalos diplomáticos entre las casas reales. Los objetos que se presentaban en estas colecciones carecían del valor estético de los modelos clásicos, pues respondían casi con exclusividad al gusto por lo exótico, más que por lo bello. Esta predilección no tardará en desembocar en una nueva tendencia arqueológica denominada anticuarismo, que llega a su punto álgido en el siglo XVIII.

La figura del anticuario surge en Inglaterra y coincide con la centralización del Estado que la dinastía Tudor acomete en la primera mitad del siglo XVI. Los anticuarios provienen por lo general de la incipiente burguesía, encargada de las 
labores administrativas, comerciantes o artesanos que dedican parte de sus recursos económicos y tiempo libre a guardar e interpretar las antigüedades locales, coleccionar objetos exóticos y recopilar leyendas autóctonas por encargo de la corona. A partir de 1533 se creó en Inglaterra la figura del Anticuario Real que se dedicaba a recopilar volúmenes dispersos por bibliotecas monásticas y a elaborar una colección de objetos hallados en yacimientos prehistóricos. El anticuario William Camden (1551-1623) tomó el relevo en el cargo y se dedicó a elaborar la primera planimetría topográfica de Inglaterra. Candem fue miembro fundador de la Societies of Antiquaries que se crea en el año 1572, con el fin de garantizar el estudio de las antigüedades nacionales. John Aubrey, sucesor de Candem, alcanzó especial celebridad por sus estudios de Stonehenge. Para él, este megalito tenía una función mágica y de carácter druídica. Los siguientes anticuarios que ocupan el puesto complementarán las labores de sus antecesores, aunque sin realizar grandes actividades arqueológicas.

La evolución del anticuarismo hacia actividades arqueológicas de carácter sistemático se origina en Escandinavia, bajo el amparo de las Sociedades de Anticuarios y de las coronas que surgen tras la separación de Suecia Noruega y Dinamarca en 1523.

Para estas nuevas naciones la estimulación de los estudios históricos y el interés por los monumentos antiguos contribuía a aportar grandeza, valor y unidad a sus gobiernos. Este hecho explica que la corona favorezca la figura de anticuario real (a imagen del modelo inglés), al que se otorgan prerrogativas y subvenciones para llevar a cabo expediciones sistemáticas sobre las numerosas ruinas estatales que, se suponían, databan de la Edad del Hierro.

Con este apoyo estatal, anticuarios como Johan Bure (1568-1652) y Ole Worm (1588-1654) propiciaron un importante avance de la investigación arqueológica, estudiando restos materiales muy antiguos. Los resultados de estas investigaciones sistemáticas dieron lugar a museos donde se exponían las piezas halladas, así como a la promulgación de leyes que aseguraban la protección de los principales monumentos antiguos. 
Durante el siglo XVIII el pensamiento europeo evoluciona gradualmente hasta situarse en el centro del cambio económico, social y cultural que acompañaría al paso de la Era Moderna a la Era Contemporánea. Así, la filosofía ilustrada sienta las bases de la visión evolucionista de la historia humana, lo que hace que se tome especial interés por los objetos líticos y las interpretaciones cronológicas. Podría decirse que la filosofía de la Ilustración desempeña una función de impulso muy similar a la llevada a cabo por las coronas escandinavas para el anticuarismo de Europa Noroccidental. Stuart Piggot realiza un estudio sobre el anticuario William Stukeley (1687-1718) en 1950 en el que se observa la influencia de la Ilustración, tanto en sus actuaciones sistemáticas como en sus interpretaciones enfocadas a crear una cronología más exacta de la historia del ser humano. Este nuevo empuje de la escuela anticuarista europea contribuye al avance de la investigación prehistórica, así como a consolidar la idea de que el ser humano podría haber habitado la Tierra durante mucho más tiempo de lo que hasta el momento se había pensado.

A finales del siglo XVIII el Romanticismo, asentado en las regiones de Europa noroccidental, estimula el interés por la arqueología de la muerte. Este interés se extenderá rápidamente a lo largo del Nuevo Mundo. Desde el descubrimiento de América los investigadores se centraron en desentrañar cómo, cuándo y de dónde habían llegado los nativos. Durante los siglos XVI, XVII y XVIII las explicaciones variaban según el país europeo que hubiera colonizado el territorio y los intereses que tuvieran para con las poblaciones oriundas. Cabe destacar que en todos los casos las incursiones arqueológicas fueron escasas y la tónica general pasaba por destruir todos los monumentos antiguos, por ser considerados testigos precristianos y, por lo tanto, paganos. Una de las más importantes excepciones que encontramos a este respecto lo constituye la colección de piedra pulimentada del periodo arcaico reciente que fueron encontrados en 1700 en Trois-Rivières, Quebec (Trigger, 1992, p. 74).

El tercer presidente de los Estados Unidos, Thomas Jefferson (1743-1826), protagoniza el primer ejemplo de arqueología sistemática en América. En 1784 dirigió la "primera excavación científica de la historia de la arqueología" (Renfrew, 1998, p. 21). Los eruditos norteamericanos consideraban que los cientos de túmulos situados al este del Mississippi habían sido construidos por una raza mítica, denominada Constructores de Túmulos. 
Jefferson, sin embargo, no dudó en cuestionar esta hipótesis adoptando un enfoque científico y contrastando la información con la evidencia concreta que le facilitó la sección transversal del túmulo que se encontraba en su propiedad de Monticello, en Charlottesville, Virginia. Allí consiguió recuperar restos humanos de diferentes capas estratigráficas a partir de la aplicación de cuidadosos métodos de extracción. Esto le llevó a expresar dos hipótesis que han continuado vigentes hasta el día de hoy: los nativos americanos construyeron los túmulos como monumentos funerarios y estos fueron reutilizados en muchas ocasiones a lo largo del tiempo (Renfrew, 1998, p. 21).

El naturalista William Bartram estudió en 1789 las estructuras ceremoniales de los indios del sureste de los Estados Unidos como base para la interpretación de los yacimientos prehistóricos de la región. Aunque faltaban documentos arqueológicos, la coexistencia de los investigadores con los pueblos prehistóricos facilitó la reconstrucción del pasado a través de la etnología. Como Alcina explica, la importancia de Bartram no radica tanto en las conclusiones de su investigación como en su labor como pionero a la hora de utilizar la etnología comparada para extraer conclusiones históricas (1989, p. 24).

A pesar del avance que supuso para la reconstrucción del pasado a partir de fuentes materiales (los resultados de las investigaciones de Stukeley, Jefferson o Edmund Halley) el hecho de no poder ser confirmados por las fuentes escritas les restó credibilidad. Esto nos da una idea de la dependencia que se tenía aún de los documentos textuales para la investigación histórica.

Este hecho es objeto de reflexión constante, como evidencian las siguientes palabras de Colt Hoare: "poseemos evidencia de la más lejana antigüedad testimoniada por los túmulos de Wiltshire, pero no sabemos nada acerca de las tribus a los que pertenecían, eso es lo único sólido" (Trigger, 1992, p. 75). El anticuario danés Nyerup también se expresaba en términos similares al afirmar que:

Todo lo que nos ha sido legado del paganismo está envuelto en una espesa niebla; pertenece a un espacio de tiempo que no podemos medir. Sabemos que es mas antiguo que la cristiandad, pero no sabemos si esa antigüedad es un par de años o un par de siglos, o incluso más de un milenio, no podemos hacer más que conjeturas (Trigger, 1992, pp. 75-76) 
El siglo XIX comienza con la idea subyacente de que la falta de documentos escritos no es sino un lastre que los investigadores deben soltar antes de seguir avanzando en cuanto a la interpretación arqueológica se refiere. A este respecto resulta pertinente mencionar las palabras de J. Dobrovsky cuando afirma que los hallazgos arqueológicos son "documentos parlantes" que pueden iluminar por sí mismos las áreas de oscuridad a las que no llega la luz arrojada por los textos escritos disponibles (Trigger, 1992, p. 76). A pesar de que no tuvo éxito al intentar poner en práctica sus ideas y del hecho de que sus palabras no gozarán de ningún eco en ese momento, serán un precedente de los cambios que se avecinan en el mundo de la arqueología.

A lo largo del siglo XIX comienza la consolidación de la arqueología como disciplina científica. Citando a García (2014),

\begin{abstract}
Al principio no existía la arqueología. Esta disciplina que por méritos propios ha ganado su puesto entre las ciencias sociales se revistió de una metodología y de unos objetivos que empezaron a definir su profesionalización en la segunda mitad del siglo XIX, y que no se consolidaron con validez hasta el siglo pasado (p. 14)
\end{abstract}

\title{
Conclusiones
}

En primer lugar, a lo largo del presente artículo hemos esbozado una somera, aunque comprehensiva visión panorámica acerca del nacimiento, desarrollo y evolución de la arqueología a lo largo del tiempo. Consideramos que esta labor resulta fundamental de cara a entender el trabajo arqueológico; al mismo tiempo que constituye un paso previo fundamental y casi ineludible antes de enfrentarse al trabajo de campo en arqueología o al estudio de los hallazgos arqueológicos a día de hoy. La importancia de conocer la historia de la arqueología viene dada tanto por las dificultades que incluso en el momento presente entraña ofrecer una definición clara de este campo científico como por el hecho de que la práctica arqueológica contemporánea, eminentemente científica y apoyada continuamente en campos científicos dispares (como puedan ser la biología o la química) no hubiera sido nunca posible sin el largo recorrido transitado por la curiosidad del ser humano por conocer su pasado a través de los restos materiales que hemos estudiado en este trabajo. 
Además, desde una perspectiva sociocultural, conocer la historia de la arqueología nos permite darnos cuenta no solo del valor incalculable que tienen para nosotros los restos materiales que nos legaron nuestros antepasados sino también entender cómo a lo largo de la historia muchas veces estos restos (junto con su valor y contexto histórico) han servido para sustentar ideas y concepciones de índole religiosa, social o política.

Por otra parte, nos gustaría expresar nuestra gratitud y deuda intelectual a aquellos pioneros de la arqueología que, sin formación específica, medios materiales ni modernas técnicas científicas se valieron de su curiosidad, intuición y titánico esfuerzo para salvaguardar la memoria del pasado, al mismo tiempo que lograron convencer a los estados de la necesidad de rescatar, valorar y estudiar el pasado.

Para concluir, no podemos dejar de reconocer que muchos de estos arqueólogos vocacionales, sin los que la ciencia arqueológica moderna no existiría hoy, provenían de muy diversos ámbitos. En otras palabras, ya desde los orígenes de la arqueología ha resultado evidente que la del arqueólogo es una tarea multidisciplinar y que cuántos más científicos provenientes de los más diversos campos aúnen esfuerzos, mayor será el avance de la arqueología y, con él, nuestro conocimiento de los seres humanos que habitaron la tierra en el pasado. En otras palabras, más sabremos de la historia, con el consiguiente descubrimiento de nosotros mismos que esta siempre nos regala. 


\section{Notas}

1 Debido a que en este momento no existían unos estudios específicos en Arqueología, los primeros investigadores desarrollaban sus trabajos a partir de sus conocimientos en estudios como la geología o la biología.

${ }^{2}$ Bruce Trigger recoge en su libro Historia del Pensamiento Arqueológico el caso del físico y geógrafo Pausanias, que, si bien describe las ruinas de la Edad del Bronce de Tirinto y Micenas, alude a ellas siguiendo la opinión de que "apenas valía la pena mencionarlas". El mismo Pausanias advierte también que la lanza de Aquiles, ubicada en el templo de Atenea en Phaselis era de bronce, esto corrobora la afirmación literaria de que los guerreros de época homérica utilizaban utillaje bélico de este material.

3 Aunque Sir Evans era un extraordinario conocedor de la obra de Homero, así como de otros tantos autores clásicos, para buscar las ruinas de la civilización minoica se apoyó fundamentalmente en la Odisea.

4 A este respecto, cabe señalar que en un manuscrito británico del siglo XV se halló un grabado que muestra a Merlín erigiendo Stonehenge. Esto entronca el monumento megalítico de la Edad del Bronce con las leyendas artúricas (Trigger, 1992, p. 41). 


\section{Referencias}

Alcina, J. (1989). Arqueología Antropológica. Madrid: Akal.

Bianchi, R. (1982). Introducción a la Arqueología Clásica como Historia del Arte Antiguo. Madrid: Akal.

Cline, E. (2018). Tres piedras hacen una pared: historias de la arqueología. Barcelona: Crítica

Dyson, S. (2008). En busca del pasado clásico: una historia de la arqueología del mundo clásico en los siglos XIX y XX. Barcelona: Ariel.

Daux, G. (1948). L'étapes de l'archéologie. París: Presses Universitaires de France.

García, J. (2014). Breve historia de la arqueología. Madrid: Ediciones Nowtilus.

Laming-Emperaire, A. (1984). La Arqueología Prehistórica. Barcelona: Martínez Roca.

Morales, F. (1990). Historia del Descubrimiento y Conquista de América. Madrid: Gredos

Piggot, S. (1950). William Stukeley: An Eighteenth-Century Anticuary. Oxford: Oxford University Press.

Quirós, J. (2013). La Materialidad de la Historia. La arqueología en los inicios del siglo XXI. Barcelona: Akal.

Renfrew, C. y P. Bahn (1998). Arqueología: Teorías, Métodos y Práctica. Madrid: Akal.

Rodanés, J. (1988). La Prehistoria: Apuntes sobre Concepto y Método. Zaragoza: Universidad de Zaragoza. 
Shakespeare, W. (1999). The Complete Works of William Shakespeare. Hertfordshire: Wordsworth.

Trigger, B. (1992). Historia del Pensamiento Arqueológico. Barcelona: Crítica.

Tucídides. (2008). Historia de la Guerra del Peloponeso. Madrid: Alianza.

Vera, E. (2011). La arqueología en los años del Renacimiento. Actas de las Octavas Jornadas de Patrimonio Arqueológico de la Comunidad de Madrid (pp. 183-188). Madrid.

Willey, G. y Sabloff, J. (1974). A History of American Archaeology. San Francisco: W. H. Freeman.

\section{Agradecimientos}

Me gustaría expresar mi agradecimiento al Dr. Martín de la Cruz, Catedrático de Prehistoria de la Universidad de Córdoba, por su confianza y asesoramiento a lo largo de mi investigación doctoral. 